\title{
From clinical reasoning to effective clinical decision making-new training methods
}

\author{
Patricia P. Wadowski ${ }^{1}$, Barbara Steinlechner ${ }^{2}$, Arno Schiferer ${ }^{2}$ and \\ Henriette Löffler-Stastka ${ }^{3 *}$ \\ ${ }^{1}$ Department of Clinical Pharmacology, Medical University of Vienna, Vienna, Austria, ${ }^{2}$ Division of Cardiothoracic and \\ Vascular Anaesthesia and Intensive Care, Medical University of Vienna, Vienna, Austria, ${ }^{3}$ Department of Psychoanalysis and \\ Psychotherapy, Medical University of Vienna, Vienna, Austria
}

Keywords: eLearning, teaching case, clinical reasoning, acute thrombocytopenia, residency

\section{The Clinical Problem}

Identification of causes and immediate adjustment to treatment of acute thrombocytopenia occurring in patients in the intensive care unit is required to avoid imminent complications. Hence it is important to train awareness and clinical decision making of students in the medical curriculum. Therefore, real-life cases were transferred into an interactive eLearning platform comprising the steps of patient assessment and therapeutic decisions.

Heparin-induced platelet count decrease is an immune-mediated prothrombotic disorder, resulting from an adverse drug reaction (Kelton and Warkentin, 2008). After cardiac surgery antibodies against circulating heparin-platelet factor (PF) four complexes develop in up to $50 \%$. Patients experience a risk of $1-5 \%$ to acquire clinical symptoms of heparin-induced thrombocytopenia (HIT) (Warkentin et al., 2000; Linkins et al., 2012). Due to complications, mortality rates are high and amount to 5-10\% (Kelton and Warkentin, 2008; Kelton et al., 2013).

As clinical teaching case a 59-year-old male patient is presented, who was admitted to the intensive care unit (ICU) of the General Hospital of Vienna on extracorporeal life support (ECMO). The man underwent bypass surgery six days ago in a peripheral hospital and is concomitantly suffering from an active infection. On the fourth day at ICU a platelet count decrease has been noticed.

\section{Identification of the Problem}

This article was submitted to Educational Psychology, a section of the journal Frontiers in Psychology

Received: 25 February 2015 Accepted: 01 April 2015 Published: 21 April 2015

Citation:

Wadowski PP, Steinlechner B, Schiferer $A$ and Löffler-Stastka $H$ (2015) From clinical reasoning to effective clinical decision making-new training methods. Front. Psychol. 6:473. doi: 10.3389/fpsyg.2015.00473

Students are now challenged to identify possible differential diagnoses and further to apply the 4Ts-scoring system. The 4Ts comprise the components Thrombocytopenia, Timing, Thrombosis, and other causes of thrombocyte decrease (Lo et al., 2006; Cuker et al., 2012). Clinical manifestation of HIT is usually characterized by a platelet count decline of $50 \%$ or more in $24 \mathrm{~h}$, and moderate to severe thrombocytopenia, which is evoked by disseminated intravascular coagulation accompanied with micro- or macro- embolic events (Warkentin, 2015). Thrombocytopenia after cardiac surgery is expected to occur on the first postoperative days (nadir platelet counts up to 4 days after surgery) (Warkentin, 2015). In contrast, the onset of heparin-associated thrombocytopenia typically emerges 5-10 days after drug administration.

Abbreviations: AKIM, general hospital information management (a clinical database); ECMO, extracorporeal life support; ELISA, enzyme-linked immunosorbent assay; GCS, Glasgow Coma Score; HIT, heparin-induced thrombocytopenia; ICU, intensive care unit; IgG, immunoglobulin G; PF 4, platelet factor 4; RASS, Richmond Agitation Sedation Scale. 
Two patterns are described: a biphasic curve of platelet count course, where a second thrombocyte fall begins about 4 days after surgery or a persistence of thrombocytopenia longer than 4 days post-operatively (Lillo-Le Louet et al., 2004). Furthermore, HIT is associated with thrombotic events in up to $75 \%$ of patients, where severe and often atypical thrombosis (e.g., bilateral deep vein thrombosis, pulmonary embolism, arterial thrombosis followed by ischemic limb necrosis) is observed (Warkentin et al., 1995; Warkentin, 2015).

\section{Disease Pathophysiology}

The basis of clinical reasoning is a profound knowledge of disease pathomechanisms and evoked complications. It is important to realize that HIT is a prothrombotic disorder, mediated by IgG binding to conformationally exposed epitopes on PF4, a chemokine secreted by activated platelets. The circulating PF4heparin- antibody complexes cross-link Fc-receptors expressed on the cell surface of mainly platelets and monocytes. Microparticles containing procoagulant proteins are released and promote further activation of the coagulation cascade (Kelton et al., 2013). The pathophysiology of HIT is demonstrated using flowcharts of the described processes.

\section{Clinical Decision Making}

Clinical decision making should proceed based on the results of the 4T-score-along the clinical problem based on associative and procedural learning processes: This scoring system has a high negative predictive value, hence it is recommended to continue heparin treatment in patients scored below four points (Alatri et al., 2012; Cuker et al., 2012). In cases of high clinical HIT- suspicion (scoring above four points), alternative anticoagulation treatment has to be immediately initiated. With the help of multiple-choice questions students are instructed to discontinue the heparin infusion instantly and change to the direct thrombin inhibitors argatroban (as first-line choice) or bivalirudin in patients with hepatic impairment (Coutre et al., 2015). Other treatment options are the factor Xa inhibitors danaparoid or fondaparinux (Linkins et al., 2012; Coutre et al., 2015). Furthermore, students' attention is drawn to identify all possible sources of heparin (coating of the suction and irrigation systems/catheters). For this form of question-driven learning multiple-choice questions are used, including feedback for each question in order to provide stepwise help.

\section{Laboratory Analyses}

After clinical assessment, blood samples should be sent to the medical laboratory. It is important to fill in the form correctly and to communicate the $4 \mathrm{~T}$ score and a brief patient history as well as the clinical course to the Laboratory Physicians. At the Department of Blood Group Serology of the Medical University of Vienna the analyses are adapted to the points achieved in the 4Ts score; quicktests (rapid lateral flow tests) as screening for patients scored below four points and ELISA assays are performed.

\section{Interdisciplinary Questions}

Patients suspected of heparin-induced thrombocytopenia need continuous monitoring with regard to platelet count and new thrombosis (Alatri et al., 2012). Neurological status assessment shall be performed at least once daily and herein we also recommend the use of the Glasgow Coma Score (GCS) and the Richmond Agitation Sedation Scale (RASS) (Teasdale and Jennett, 1974; Reade and Finfer, 2014). Indices of thrombosis often require consultation and close cooperation with internal specialists/ neurologists and vascular surgeons for thrombectomy performance, if needed.

\section{The Clinical Course of the Patient}

The anticoagulation of the patient was immediately changed to a direct thrombin inhibitor and patient hematological and neurological status monitored closely. Platelet count courses (in relation to fibrinogen) are shown to students with interactive evaluation possibility. For training purposes, the case includes a patient suffering from instantly occurring HITcomplications, i.e., intracerebral thromboembolism, where students are confronted with the symptoms and possible diagnostic methods.

\section{Concept and Methodological Approach}

Clinical reasoning is considered to consist of intuitive and analytical components (Croskerry, 2009; Kassirer, 2010). Research on mental processes suggests that disease patterns are stored in "frames," "clinical scenarios," "semantic networks/qualifiers," or "illness scripts." Repeated presentation and exercising of clinical cases is known to be crucial for an efficient learning process (Norman, 2005; Kassirer, 2010).

Implementation of the interactive case-based teaching method into the Medical Curriculum in Vienna was initiated in 2014. For teaching purposes, real-life clinical patient cases are transferred from the general hospital information management into an online platform provided by the Medical University of Vienna. Data anonymisation is performed automatically through the transmission system. Teachers and students provide knowledge to add background information, program relevant questions as well as a feedback system to give direction to the reasoning process.

Results associated with the evaluation of these newly adjusted and improving curriculum-elements (Turk et al., 2015) after introducing case-based exercises and case-based questioning showed a positive steering effect on the learning process and fostered the acquisition of associative and procedural knowledge (Seitz and Löffler-Stastka, 2015). The main effect on the learning process was given through the implementation of affectively involving case-based exercises discussed in seminars fostering clinical reasoning processes (Parth et al., 2014) and preparing students for patient-centered thinking in the case of following bedside teaching methods. 


\section{Message}

To summarize, students should practice everyday patient evaluation and learn the value of interdisciplinary team communication as well as the application of the 4Ts score and crucial disease pathophysiology.

In the future, the concept of interactive case-based learning methods should be developed further and established as a training

\section{References}

Alatri, A., Armstrong, A. E., Greinacher, A., Koster, A., Kozek-Langenecker, S. A., Lance, M. D., et al. (2012). Results of a consensus meeting on the use of argatroban in patients with heparin-induced thrombocytopenia requiring antithrombotic therapy-a European Perspective. Thromb. Res. 129, 426-433. doi: 10.1016/j.thromres.2011.11.041

Coutre, S., Leung, L. L. K., and Tirnauer, J. S. (2015). Management of HeparinInduced Thrombocytopenia. Available online at: http://www.uptodate. com/contents/management-of-heparin-induced-thrombocytopenia - H37. [Accessed on 248 11.02.2015].

Croskerry, P. (2009). A universal model of diagnostic reasoning. Acad. Med. 84, 1022-1028. doi: 10.1097/ACM.0b013e3181ace703

Cuker, A., Gimotty, P. A., Crowther, M. A., and Warkentin, T. E. (2012). Predictive value of the 4Ts scoring system for heparin-induced thrombocytopenia: a systematic review and meta-analysis. Blood 120, 4160-4167. doi: 10.1182/blood2012-07-443051

Kassirer, J. P. (2010). Teaching clinical reasoning: case-based and coached. Acad. Med. 85, 1118-1124. doi: 10.1097/ACM.0b013e3181d5dd0d

Kelton, J. G., Arnold, D. M., and Bates, S. M. (2013). Nonheparin anticoagulants for heparin-induced thrombocytopenia. N. Engl. J. Med. 368, 737-744. doi: 10.1056/NEJMct1206642

Kelton, J. G., and Warkentin, T. E. (2008). Heparin-induced thrombocytopenia: a historical perspective. Blood 112, 2607-2616. doi: 10.1182/blood-2008-02078014

Lillo-Le Louet, A., Boutouyrie, P., Alhenc-Gelas, M., Le Beller, C., Gautier, I., Aiach, M., et al. (2004). Diagnostic score for heparin-induced thrombocytopenia after cardiopulmonary bypass. J. Thromb. Haemost. 2, 1882-1888. doi: 10.1111/j.1538-7836.2004.00949.x

Linkins, L. A., Dans, A. L., Moores, L. K., Bona, R., Davidson, B. L., Schulman, S., et al. (2012). Treatment and prevention of heparin-induced thrombocytopenia: antithrombotic therapy and prevention of thrombosis, 9th ed: American college of chest physicians evidence-based clinical practice guidelines. Chest 141(Suppl. 2), e495S-e530S. doi: 10.1378/chest.11-2303

Lo, G. K., Juhl, D., Warkentin, T. E., Sigouin, C. S., Eichler, P., and Greinacher, A. (2006). Evaluation of pretest clinical score (4 T's) for the diagnosis of heparininduced thrombocytopenia in two clinical settings. J. Thromb. Haemost. 4, 759-765. doi: 10.1111/j.1538-7836.2006.01787.x program for residents. Case-based question-driven learning provides a solid basis for associative and procedural learning that is necessary in clinical reasoning processes. In order to provide a diversity of case-based learning materials several other domains establish their learning cases in eLearning/blended learning scenarios. The basic didactic principle and the institutional framework were installed project-related (Turk et al., 2015) and received merits within the award-system for communication 2015.

Norman, G. (2005). Research in clinical reasoning: past history and current trends Med. Educ. 39, 418-427. doi: 10.1111/j.1365-2929.2005.02127.x

Parth, K., Hrusto-Lemes, A., and Löffler-Stastka, H. (2014). Clinical reasoning processes and authentic clinical care for traumatised patients. J. Trauma. Stress Disord. Treat. Sci. Technol. 3, 4. doi: 10.4172/2324-8947.1000130

Reade, M. C., and Finfer, S. (2014). Sedation and delirium in the intensive care unit. N. Engl. J. Med. 370, 444-454. doi: 10.1056/NEJMra1208705

Seitz, T., and Löffler-Stastka, H. (2015). Do our medical students even want e-learning? A user rated evaluation of case based e-learning in undergraduate medical education at the medical university of Vienna. Adv. Soc. Sci. Res. J. 2, 156-161. doi: 10.14738/assrj.23.1003

Teasdale, G., and Jennett, B. (1974). Assessment of coma and impaired consciousness. A Pract. Scale Lancet 2, 81-84. doi: 10.1016/S0140-6736(74) 91639-0

Turk, B. R., Krexner, R., Otto, F., Wrba, T., and Löffler-Stastka, H. (2015). Not the ghost in the machine: transforming patient data into e-learning cases within a case-based blended learning framework for medical education. Proc. Soc. Behav. Sci.

Warkentin, T. E. (2015). Heparin-induced thrombocytopenia in critically III patients. Semin. Thromb. Hemost. 41, 49-60. doi: 10.1055/s-0034-1398381

Warkentin, T. E., Levine, M. N., Hirsh, J., Horsewood, P., Roberts, R. S., Gent, M., et al. (1995). Heparin-induced thrombocytopenia in patients treated with low-molecular-weight heparin or unfractionated heparin. N. Engl. J. Med. 332, 1330-1335. doi: 10.1056/NEJM199505183322003

Warkentin, T. E., Sheppard, J. A., Horsewood, P., Simpson, P. J., Moore, J. C., and Kelton, J. G. (2000). Impact of the patient population on the risk for heparin-induced thrombocytopenia. Blood 96, 1703-1708.

Conflict of Interest Statement: The authors declare that the research was conducted in the absence of any commercial or financial relationships that could be construed as a potential conflict of interest.

Copyright (C) 2015 Wadowski, Steinlechner, Schiferer and Löfler-Stastka. This is an open-access article distributed under the terms of the Creative Commons Attribution License (CC BY). The use, distribution or reproduction in other forums is permitted, provided the original author(s) or licensor are credited and that the original publication in this journal is cited, in accordance with accepted academic practice. No use, distribution or reproduction is permitted which does not comply with these terms. 